\title{
Evaluation of the Impact of Truck Overloading on Flexible Compacted Gravel Lateritic Soil's Pavements by FEM with ${\text { Cast } 3 M^{\odot}}^{\odot}$
}

\author{
Fatou Samb1', Meissa Fall1, Yves Berthaud'2, Farid Bendboudjema ${ }^{3}$ \\ ${ }^{1}$ Laboratoire de Mécanique et Modélisation, UFR Sciences de l'Ingénieur, Université de Thiès, Thiès, Sénégal \\ ${ }^{2}$ Sorbonne Universités, UPMC Univ Paris 06, UMR 7190, d'Alembert, F-75005, Paris, France \\ ${ }^{3}$ Laboratoire de Mécanique et de Technologie, Ecole Normale Supérieure de Cachan, Cachan, France \\ Email: fatou.samb@univ-thies.sn
}

Received 25 September 2014; revised 25 October 2014; accepted 18 November 2014

Copyright (C) 2015 by authors and Scientific Research Publishing Inc.

This work is licensed under the Creative Commons Attribution International License (CC BY).

http://creativecommons.org/licenses/by/4.0/

(c) (†) Open Access

\begin{abstract}
Within the framework of a FEM of the nonlinear behavior of lateritic pavement of Senegal, the effect of truck overloading is studied to estimate its impact on the deformability of road pavement on compacted gravel lateritic soils. For that purpose, various loading conditions were tested to measure the impact on the critical response parameters of road pavement design. The implementation of the models was realized with Cast3M ${ }^{\odot}$. This study allowed us to point out that the observed variations are linear and would help to plan in advance the impact of axle overloads for a better evaluation within the framework of the mechanistic (M. E.) design of pavements.
\end{abstract}

Keywords

FEM, Axle Overload, Nonlinear Behavior, Gravel Lateritic Soil

\section{Introduction}

The regulation number 14/2005/CM/UEMOA of WAEMU (West African Economic and Monetary Union) of December $16^{\text {th }}$, 2005 concerning the harmonization of standards and control procedures of truck volumes, weights and axle loads of heavy goods vehicles in the member states of the Union, set the axle load to 12 tons for a single axle with dual-wheels (Uemoa, 2005 [1]). However, recent studies showed that this recommended official load is far from being respected. Indeed, $60 \%-70 \%$ of heavy trucks are overloaded and have significant

How to cite this paper: Samb, F., Fall, M., Berthaud, Y. and Bendboudjema, F. (2015) Evaluation of the Impact of Truck Overloading on Flexible Compacted Gravel Lateritic Soil's Pavements by FEM with Cast3M ${ }^{\odot}$. Geomaterials, 5, 19-24.

http://dx.doi.org/10.4236/gm.2015.51002 
contribution in the degradation of roads. The objective of this study is to determine the critical response parameters of lateritic roads materials submitted to various conditions of axle overload. The standard axle load is $130 \mathrm{kN}$ (13 tons) for a single axle with dual-wheels (Bceom-Cebtp, 1984 [2]). The reference load is uniformly distributed on two circles whose centers are from $37.5 \mathrm{~cm}$ away from each other. The calculation of the stresses and the strains is done for a typical load of 6.5 tons exercising a vertical pressure $q$ uniformly distributed on two circles with: $a=12.5 \mathrm{~cm} ; l=3 \times a=37.5 \mathrm{~cm}$ and $q=6.62$ bars. The reference load for the calculations is represented by the Figure 1 .

The reference axle is varied from 13 to 20 tons to take into account the overloading. The effect of a single wheel is tested with a tire pressure of $0.662 \mathrm{MPa}$ for the load of 13 tons and respectively $0.764 \mathrm{MPa}$, $0.917 \mathrm{MPa}$ and 1.019 MPa respectively for axle loads of the 15, 18 and 20 tons (Samb, 2014 [3]).

\section{Geometry, Materials and Algorithm of Calculations}

The structure consists of a $80 \mathrm{~mm}$ thick bituminous concrete, a $200 \mathrm{~mm}$ thick base layer of lateritic gravels treated or not, a $250 \mathrm{~mm}$ thick subbase of untreated lateritic gravels and of a sandy subgrade of infinite thickness. The materials of the asphalt and subgrade layer are considered linear elastic. The base and the subbase has a nonlinear elastic behavior. To take into account this non-linearity, the elastic modulus is replaced by a resilient modulus which depends on the stress level. Several formulations were suggested by using various terms of stresses (Lekarp, Isacsson, and Dawson, 2000 [4]; Kim, 2007 [5]) and showed that the models proposed by Uzan (1985) [6] and the NCHRP (2004) [7] allow to take into account the behavior of granular soils as well as fine soils. Triaxial test results on the gravel lateritic soils of Ngoundiane showed that Uzan model give the best correlations and so, the model parameters was determined for these soils.

The Uzan model expresses the resilient modulus according to the bulk stress and the deviatoric stress, which allows us to take into account the effect of the shear behavior:

$$
M_{r}=k_{1}\left(\frac{\theta}{p_{a}}\right)^{k_{2}}\left(\frac{\sigma_{d}}{p_{a}}\right)^{k_{3}}
$$

with,

$\theta=\left(\sigma_{1}+2 \sigma_{3}\right)=\left(\sigma_{d}+3 \sigma_{3}\right)=$ bulk stress;

$\sigma_{d}=\sigma_{1}-\sigma_{3}=$ deviatoric stress;

$k_{1}, k_{2}$ and $k_{3}$ : model parameters.

For the Young modulus, the maximal values of the unconfined compression tests are chosen, by considering that the gravel lateritic soils are perfectly compacted in 95\% of the Optimum Modified Proctor (OMP). For the asphalt layer and the subgrade (Young modulus $(E)$ and Poisson's ratio $(v)$ ), these values are chosen in reference to Fall, Senghor and Lakhoune (2002) [8]. The materials parameters are given in Table 1. The horizontal movements are blocked in the transverse directions (flexible boundary) and the vertical and horizontal movements are blocked in the bottom of the subgrade (stiff boundary).

For nonlinear analysis, an incremental iterative procedure is used, the tangent constitutive matrix is updated after and during each load increment (NCHRP, 2004). For this implementation, a direct incremental method of the resilient modulus with very small time steps is used. A first test showed that, for the linear method, 24 time-steps were sufficient to reach a constant result. Besides, for the nonlinear model, the tests showed that the

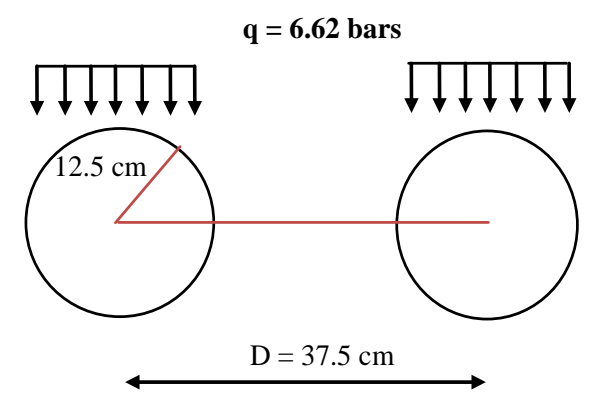

Figure 1. Schematization of the loading. 
results vary very widely according to the compulsory number of steps. From 300 steps, the values stabilize, which explains that the value of the number of steps $n$ was set to these aforesaid values. For every interval of load, the resilient modulus is given with the average of the values found for two successive stages. This algorithm is summarized in Figure 2.

Table 1. Characteristics of the axisymmetric linear and nonlinear models for the lateritic gravel soils of Ngoundiane (Samb, 2014 [3]).

\begin{tabular}{|c|c|c|c|c|c|c|}
\hline \multirow{2}{*}{ Pavement layers } & \multirow{2}{*}{$\begin{array}{c}\text { Thickness } \\
h_{i}(\mathrm{~mm})\end{array}$} & \multicolumn{2}{|c|}{ Linear model } & \multicolumn{3}{|c|}{ Nonlinear model } \\
\hline & & $v$ & $E(\mathrm{MPa})$ & $k_{1}(\mathrm{kPa})$ & $k_{2}$ & $k_{3}$ \\
\hline Asphalt & 80 & 0.35 & 1.300 & - & - & - \\
\hline Base (untreated) & 200 & 0.25 & 62 & 837.275 & 0.13 & -0.33 \\
\hline Base $2 \%$ & 200 & 0.25 & 84 & 279.074 & 0.65 & -0.50 \\
\hline Base 3\% & 200 & 0.25 & 137 & 170.052 & 0.88 & -0.56 \\
\hline Subbase (untreated) & 250 & 0.25 & 62 & 837.276 & 0.13 & -0.33 \\
\hline Subgrade & 17.500 & 0.25 & 30 & - & - & - \\
\hline
\end{tabular}

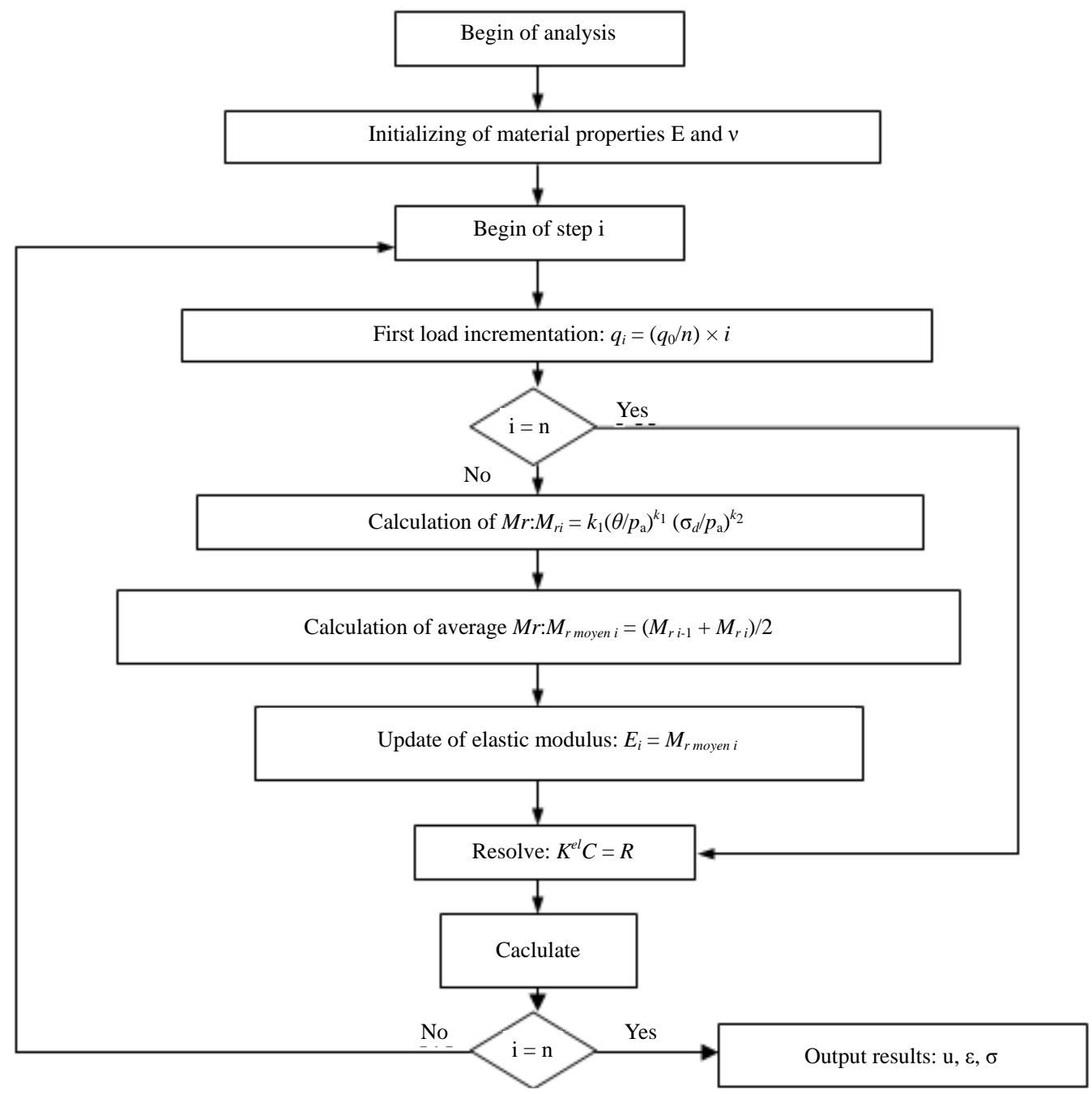

Figure 2. Calculation algorithm used in Cast3M ${ }^{\odot}$ (Samb, 2014 [3]). 


\section{Impact of Overloading on the Deflection and the Vertical Strain of the Subgrade}

The effect of overloading was studied with regard to the normalized axle load of calculation (13 tons). Figure 3(a) and Figure 3(b) and Figure 4(a) and Figure 4(b) give the variation of deflections and strains for the linear and nonlinear models. The results show a linear variation of the axle overload for both models. This proves that it is possible to know in advance the impact of the axle overload on deflections and strains of the pavement layers. We notice that the values of strains and deflections decrease according to the depth. Indeed, the values noticed at the subgrade are lower than those noticed for the other layers.

On the other hand, the impact of the axle overload seems to have more effect on deflection at the top layers (asphalt layer and base layer) than for the lower layers. It is necessary to note that the effect of a single wheel was tested. To know the total deflection and strain, it is necessary to take into account the effect of the dualwheels. Besides, the variation of deflection and deformation for a variation of the axle overload of 1, 2, 3, 5 and 10 tons is given for the linear model (Table 2). These results show the possibilities of forecasting the response parameters values by analyzing loading scenarios. For a calculated estimation, Table 3 gives a comparison of

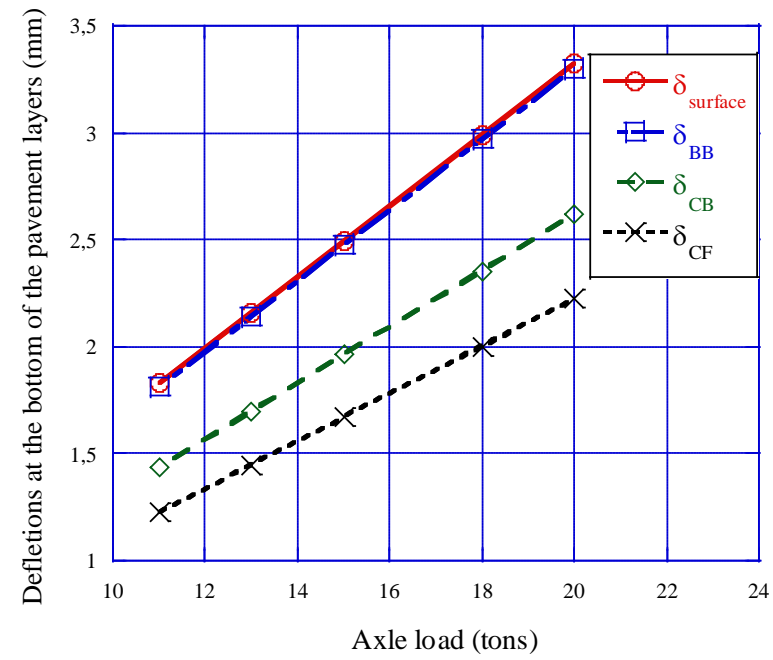

(a)

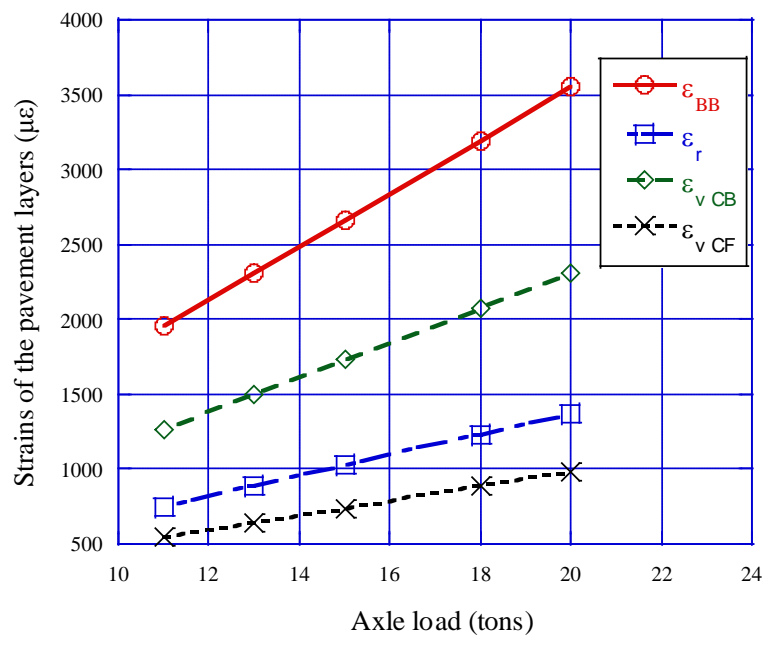

(b)

Figure 3. Variation of deflections and strains of the pavement layers (in absolute value) of the load for the 2D linear model: (a) Deflections; (b) Strains (Samb, 2014 [3]).

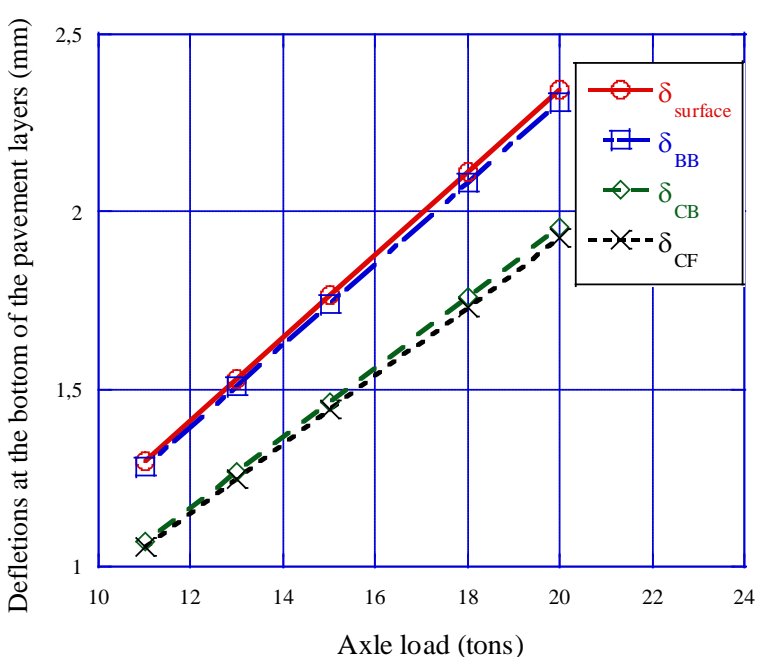

(a)

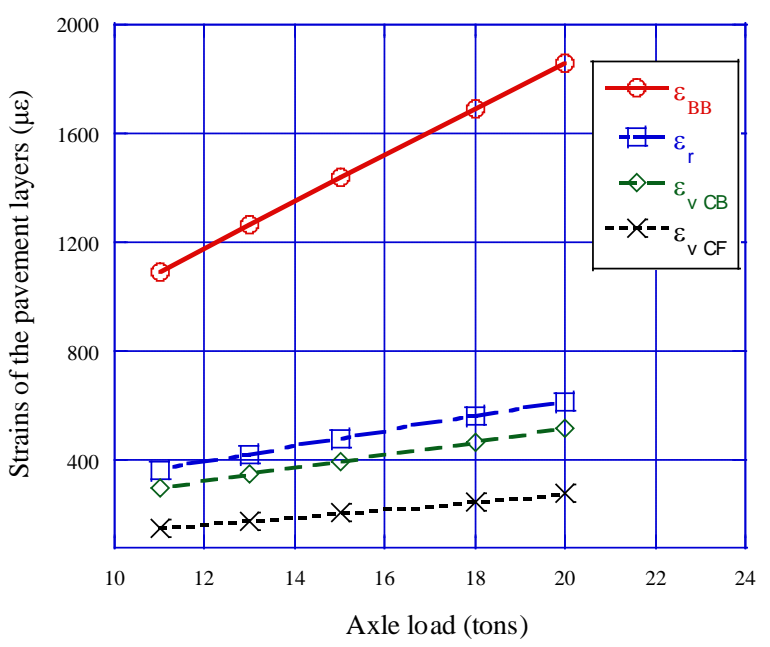

(b)

Figure 4. Variation of deflections and strains of the pavement layers (in absolute value) of the load for the 2D nonlinear model: (a) Deflections; (b) Strains (Samb, 2014 [3]). 
Table 2. Deflections and deformations caused by the pressure of a tire by tons of axle overload for the linear model and for respectively: 2, 3, 5 and 10 tons (Samb, 2014 [3]).

\begin{tabular}{cccccc}
\hline & Deflections & & \multicolumn{2}{c}{ Deflections according to the axle overload (mm) } \\
\hline & Per tons $(\mathrm{mm})$ & 2 tons & 3 tons & 5 tons & 10 tons \\
\hline$\delta_{\text {surface }}$ & -0.04877 & -0.09754 & -0.14631 & -0.24385 & -0.4877 \\
$\delta_{\mathrm{BB}}$ & -0.04877 & -0.09754 & -0.14631 & -0.24385 & -0.4877 \\
$\delta_{\mathrm{CB}}$ & -0.0227465 & -0.045493 & -0.0682395 & -0.1137325 & -0.227465 \\
$\delta_{\mathrm{CF}}$ & -0.008193 & -0.016386 & -0.024579 & -0.040965 & -0.08193 \\
\hline & Deformations & & Deformations according to the axle overload $(\boldsymbol{\mu \varepsilon})$ & 10 tons \\
\hline$\varepsilon_{\mathrm{BB}}$ & Per tons $(\mu \varepsilon)$ & 2 tons & 3 tons & 5 tons & -1374.2 \\
$\varepsilon_{r}$ & -137.42 & -274.84 & -412.26 & -687.1 & 560.705 \\
$\varepsilon_{\mathrm{CB}}$ & 56.0705 & 112.141 & 168.2115 & 280.3525 & -815.26 \\
$\varepsilon_{\mathrm{CF}}$ & -81.526 & -163.052 & -244.578 & -407.63 & -275.18 \\
\hline
\end{tabular}

Notations: BB: asphalt layer; CB: base layer; CF: subbase layer.

Table 3. Variation of the critical response due to the pressure of a tire by tons of road overload (Samb, 2014 [3]).

\begin{tabular}{ccc}
\hline & Variation per tons of overload & \\
\hline & 2D Linear & 2D Nonlinear \\
\hline$\delta_{\text {surface }}(\mathrm{mm})$ & -0.166 & -0.116 \\
$\delta_{\mathrm{BB}}(\mathrm{mm})$ & -0.165 & -0.115 \\
$\delta_{\mathrm{CB}}(\mathrm{mm})$ & -0.131 & -0.098 \\
$\delta_{\mathrm{CF}}(\mathrm{mm})$ & -0.111 & -0.097 \\
$\varepsilon_{\mathrm{VBB}}(\mu \varepsilon)$ & -177.370 & -87.685 \\
$\varepsilon_{r}(\mu \varepsilon)$ & 68.291 & 28.778 \\
$\varepsilon_{\mathrm{VCB}}(\mu \varepsilon)$ & -115.200 & -24.440 \\
$\varepsilon_{\mathrm{VCF}}(\mu \varepsilon)$ & -49.345 & -14.245 \\
$\sigma_{r}(\mathrm{MPa})$ & 0.065 & 0.019 \\
$\sigma_{\mathrm{CB}}(\mathrm{MPa})$ & -0.008 & -0.013 \\
$\sigma_{\mathrm{CF}}(\mathrm{MPa})$ & -0.002 & -0.001 \\
\hline
\end{tabular}

the variation of deflections and strains for the linear and nonlinear models by tons of axle overload. We can thus notice that the linear model gives higher strain and deflection variations and lower stress variations than for the nonlinear model.

\section{Conclusion}

The results show a linear variation of deflections and deformations at the road layers according to the variation of the axle overload. This overload seems to have more effects on deflections for the top layers level (asphalt layer and base layer) than the lower layers. It is however necessary to note that the effect of a single wheel is tested. To know total deflections and deformations, it is necessary to take into account the dual tires. These results reveal the possibility of obtaining the response values of roads by analyzing real scenarios of load as well as forecasting the impact of the axle overload on deflections and deformations of road pavements. 


\section{References}

[1] UEMOA (2005) Règlement N¹4/2005/CM/UEMOA relatif à l'harmonisation des normes et des procédures du contrôle du gabarit, du poids, et de la charge à l'essieu des véhicules lourds de transport de marchandises dans les états membres de l’Union Economique et Monétaire Ouest Africaine (UEMOA), 18-19.

[2] BCEOM-CEBTP (1984) Guide Pratique de dimensionnement dans les pays tropicaux. Ministère Français de la Coopération, $155 \mathrm{p}$.

[3] Samb, F. (2014) Modélisation par éléments finis des chaussées en graveleux latéritiques traités ou non et application au dimensionnement Mécanistique-Empirique. Thèse de Doctorat, Géotechnique, ED2DS, Université de Thiès, Thiès.

[4] Lekarp, F., Isacsson, U. and Dawson, A. (2000) State of the Art. I: Resilient Response of Unbound Aggregates. Journal of Transportation Engineering, 126, 66-75. http://dx.doi.org/10.1061/(ASCE)0733-947X(2000)126:1(66)

[5] Kim, M. (2007) Three-Dimensional Finite Element Analysis of Flexible Pavements Considering Non Linear Pavement Foundation Behavior. Dissertation, University of Illinois, Urbana.

[6] Uzan, J. (1985) Characterization of Granular Material. Transportation Research Record No. 1022, Transportation Research Board, Washington DC, 52-59.

[7] NCHRP (2004) Laboratory Determination of Resilient Modulus for Flexible Pavement Design. National Cooperative Highway Research Program (NCHRP) Project 1-28A. Transportation Research Board of National Academies.

[8] Fall, M., Senghor, B. and Lakhoune, A. (2002) Analyse de la pratique du dimensionnement rationnel des structures de chaussée au Sénégal. Influence des paramètres d'entrée dans les codes de calcul pour le renforcement des chausses. Annales du Bâtiment et des Travaux Publics, UCAD, FST, IST. 
Scientific Research Publishing (SCIRP) is one of the largest Open Access journal publishers. It is currently publishing more than 200 open access, online, peer-reviewed journals covering a wide range of academic disciplines. SCIRP serves the worldwide academic communities and contributes to the progress and application of science with its publication.

Other selected journals from SCIRP are listed as below. Submit your manuscript to us via either submit@scirp.org or Online Submission Portal.
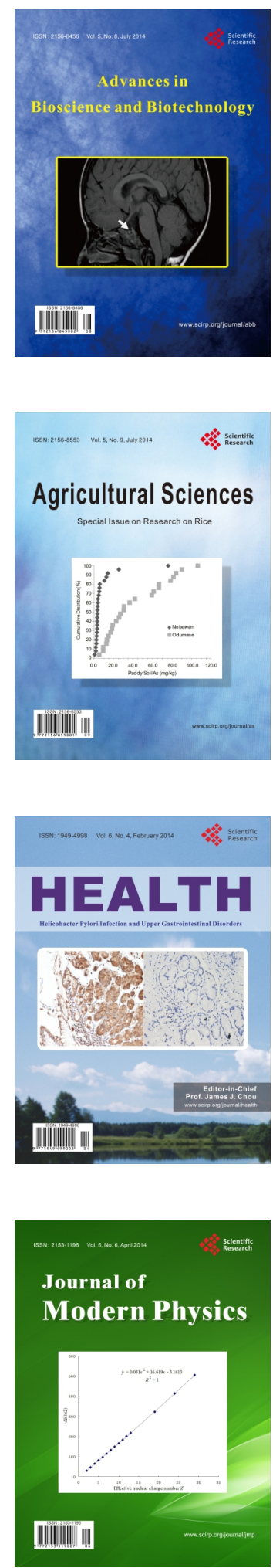
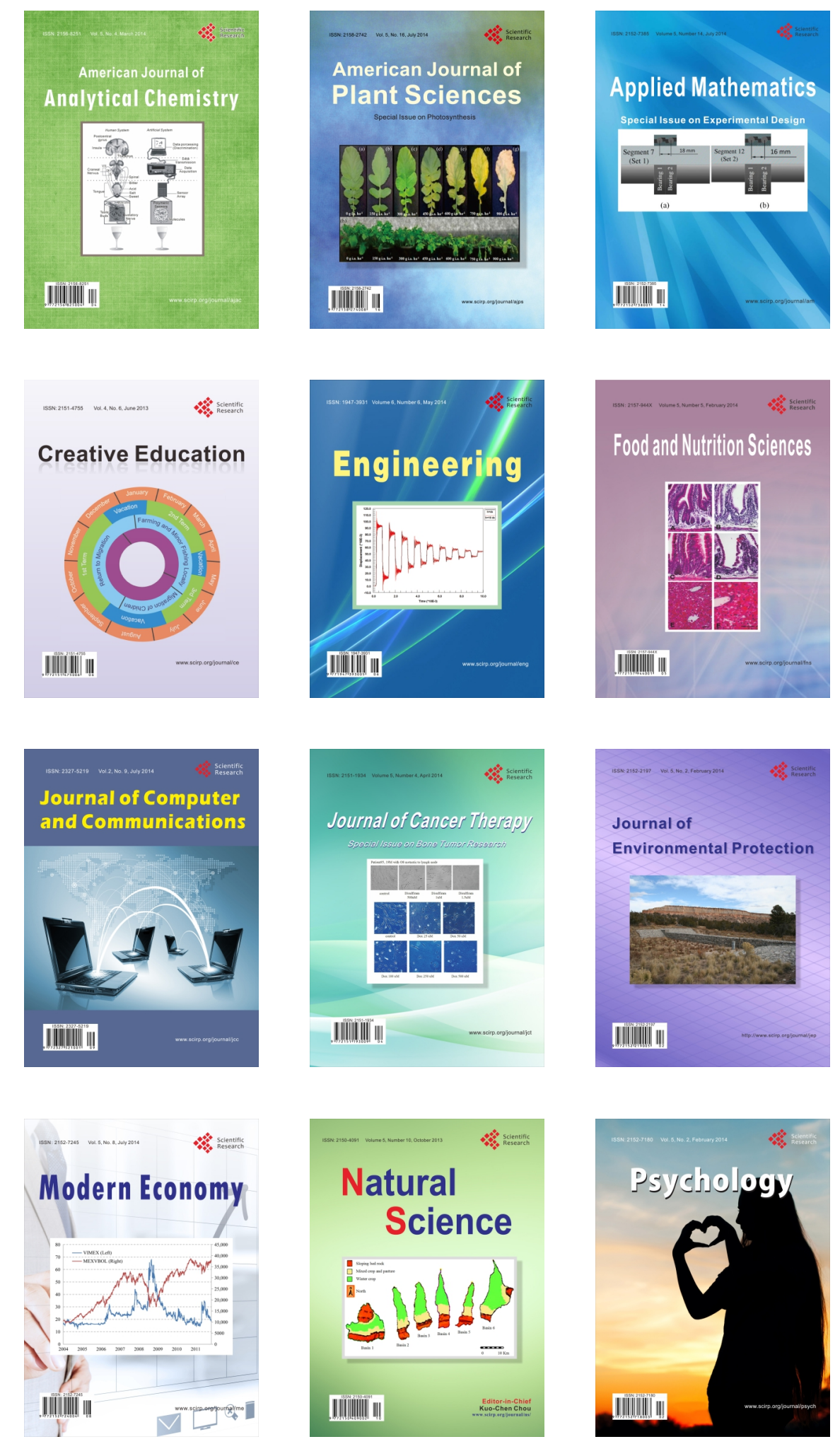